\section{Medí̈al Seilenę}

pISSN 2321-7359; eISSN 2321-7367

\title{
Impact of physical activities on quality of life among female medical students in King Abdulaziz University
}

To Cite:

Azhar A, Aldaheri RE, Alqurashi YF, Alalyani WM, Albandar AA. Impact of physical activities on quality of life among female medical students in King Abdulaziz University. Medical Science, 2022, 26, ms39e2063.

doi: https://doi.org/10.54905/disssi/v26i119/ms39e2063

\begin{abstract}
Author Affiliation:
\end{abstract}
'Professor and consultant of pediatric cardiology, Faculty of medicine, King Abdulaziz University, Jeddah, Saudi Arabia

${ }^{2}$ Medical intern, Minstry of health, Faculty of medicine, King Abdulaziz University, Jeddah, Saudi Arabia

\section{Corresponding author}

Professor and consultant of pediatric cardiology, Faculty of medicine, King Abdulaziz University,

Jeddah, Saudi Arabia

Email: azcardio@hotmail.com

Peer-Review History

Received: 18 December 2021

Reviewed \& Revised: 20/December/2021 to 16/January/2022

Accepted: 18 January 2022

Published: 19 January 2022

Peer-review Method

External peer-review was done through double-blind method.

URL: https://www.discoveryjournals.org/medicalscience

\section{(c) (1)}

This work is licensed under a Creative Commons Attribution 4.0 International License.

\author{
Ahmad Azhar ${ }^{1 凶}$, Reem Ebraheem Aldaheri², Yara Faisal \\ Alqurashi' ${ }^{2}$, Wafaa Mohammed Alalyani ${ }^{2}$, Albandari \\ Abdullah Albandar ${ }^{2}$
}

\begin{abstract}
Background: Physical activity (PE), which offers a variety of health and mental advantages, has gotten a lot of attention in Saudi society, particularly among medical students. In 2014, the prevalence of physical inactivity was found to be 66.6 percent, namely 60.1 percent for males and 72.9 percent for females in Saudi Arabia, where the prevalence of physical inactivity was found to be 66.6 percent, specifically 60.1 percent for males and 72.9 percent for females. Our goal is to show that physical activity has a significant impact on the quality of life of female medical students at King Abdulaziz University (KAU). Methodology: From September 2019 to September 2020, a cross-sectional study was undertaken. Female medical students completed a combination of two validated questionnaires: the (WHOQOL)-BREF questionnaire as a measurement tool for QOL and the (BREQ-3) for Physical Exercise Engagement. From a total of 1000 students, we selected 437 students between the ages of 18 and 25, excluding those who had graduated from medical school. Result: We observed a statistical significant relationship between PE and general health, physical fitness, and psychological well-being. Female medical students who participate in physical activity are more likely to be pleased with their physical appearance and lifestyle, as a result of which they have a high degree of confidence, motivation, and self-esteem. Conclusion: It is recommended that the entire Saudi population be made more aware of $\mathrm{PE}$, and that future studies employ other study methods for more thorough results.
\end{abstract}

Keywords: physical, activities, QOL, female, medical, Saudi

\section{INTRODUCTION}

Physical exercise (PE) is an extremely broad expression as it ranges from a simple walk to different kinds of vigorous activities. In recent years, PE has received a huge attention among saudi society including medical students. Globally, $23 \%$ of males and $32 \%$ of females aged $18+$ years were insufficiently 
physically active, where is the prevalence of physical inactivity in 2014 was found to be $66.6 \%$ specifically $60.1 \%$ for males and 72.9\% for females in Saudi Arabia (Al-Zalabani et al., 2015; WHO, 2021). PE has many benefits includes improvement in blood circulation, respiratory functioning, psychological health, habit formation and learning (Cappelen, 2014; Ferguson, 2014; Han, 2018; Alothman et al., 2021). Additionally, it can assist in controlling blood sugar and blood pressure as well as help maintaining a healthy body mass index (BMI).

Female medical students are exposed to different factors affecting their psychological and physiological life's so we are suspecting that females QoL are more affected than males; many authors reported that there is high level of depression and stress among medical students which can affect their quality of life (QOL), (Peleias et al, 2017). On other hand, QOL has many dimensions such as physical, psychological, social and environmental (Han, 2018). Based on previous studies, regular exercise has a great role in enhancing the QOL (Alkhamis et al., 2021). Recent papers were published in Iran (Talebpour et al., 2014), UK (Rodríguez-Fernández et al., 2017) and Brazil (Peleias et al., 2017) respectively showed that there is a significant association between PE and QOL. None of the previous published papers focused on the impact of a specific type of physical exercise on a definitive dimension of QOL. Also,there is no sufficient studies have been done about the physical exercise and their impact among QOL of the female medical students.

In our study we aim is to prove that physical exercise is an important factor influencing the QOL of female medical students in KingAbdulazizUniversity (KAU).

\section{METHODOLOGY}

This study was approved by the biomedical ethics committee at King Abdul-aziz University hospital (KAUH), Jeddah, Saudi Arabia. A Cross-Sectional observational study was conducted over one year from September 2019 to September 2020. A combination of two validated questionnaires: (WHOQOL)-BREF questionnaire as a measurement tool for QOL and (BREQ-3) for Physical Exercise Engagement were full-filled by female medical students. From a total of 1000 we included 437 students of all the academic years aged 18 to 25 years old, meanwhile we excluded those who graduated from medical school.

An Electronic google forms- based questionnaires were accomplished to collect personal data (age, nationality, academic year, current grade point average (GPA), marital status, medical illness, use of medications for the last year). The data were coded and processed using Microsoft Excel and the Software Statistical Package for the Social Science (SPSS) version 23. Descriptive statistics including frequencies (N), percentages (\%), mean (M) and standard deviation (SD) were used to describe the items and the study variables. Furthermore, we used an independent T-Test to test differences of the QOL based on the student's exercise.

\section{RESULTS}

The main goal of our study is to know the different effects of PE on the QOL as the p value showed to be 0.05 were considered statistically significant. Of 1000 randomly selected female medical students, 437 accepted to participate and completed the study. As shown in Table (1) that (97\%) were saudi (3\%) were non Saudi, most of them were singles (96.8\%). Their academic year varied for around $20 \%$ each. Their ages ranged between 18 and 25 years (21.64 \pm 1.86 , mean \pm SD). More than a half ( $54.4 \%)$ got a grade above 4.5 and $41 \%$ between 3.5 and 4.49 .

Table 1 Distribution of the participants according to their demographic characters, academic year and GPA

\begin{tabular}{|l|l|l|l|}
\hline \multicolumn{2}{|l|}{ Factor } & Number & $\%$ \\
\hline \multicolumn{2}{|l|}{ Age (mean \pm SD) } & Mean: 21.64 & SD: 1.86 \\
\hline \multirow{4}{*}{ Nationality } & non Saudi & 13 & 3 \\
\cline { 2 - 4 } & Saudi & 424 & 97 \\
\hline \multirow{4}{*}{ Martial statues } & Divorced & 1 & 0.2 \\
\cline { 2 - 4 } & Married & 13 & 3 \\
\cline { 2 - 4 } & Single & 423 & 96.8 \\
\hline \multirow{5}{*}{ Academic years } & 6th & 85 & 19.5 \\
\cline { 2 - 4 } & 5th & 90 & 20.6 \\
\cline { 2 - 4 } & 4th & 85 & 19.5 \\
\cline { 2 - 4 } & 3rd & 92 & 21.1 \\
\hline
\end{tabular}




\begin{tabular}{|l|l|l|l|}
\hline & 2nd & 85 & 19.5 \\
\hline \multirow{4}{*}{ GPA } & $<2.5$ & 2 & 0.5 \\
\cline { 2 - 4 } & $3.49-2.5$ & 18 & 4.1 \\
\cline { 2 - 4 } & $4.49-3.5$ & 179 & 41 \\
\cline { 2 - 4 } & $\geq 4.5$ & 238 & 54.5 \\
\hline
\end{tabular}

Table (2) shows that 310 students Exercise (70\%), and only 22\% had medical illness, $42 \%$ had medication last years. Overall the most popular physical exercise was walking $(46.1 \%)$, and $34.8 \%$ of students only exercised between 10 mints and 20 mints. As indicated in Table (3) physical exercise (PE) was measured using 16 items, 7 items achieved high level, which ranged between $(2.86 \pm 0.38)$ for item $15(2.42 \pm 0.60)$ for item 6.6 items achieved moderate level ranged between $(2.27 \pm 0.64)$ for item 16 to $(1.77 \pm 0.57)$ for item 2. Only 3 items achieved low level, which ranged between (1.41 \pm 0.61$)$ for item 10 to $(1.27 \pm 0.52)$ for item 11 . The overall mean was moderate $(2.21 \pm 0.21)$.

Table 2 Distribution of the participants according to their exercise status, medical illness, medication and exercise pattern

\begin{tabular}{|l|l|l|l|}
\hline Factor & No & N & $\%$ \\
\hline \multirow{3}{*}{ Exercise states } & Yes & 127 & 29 \\
\hline \multirow{4}{*}{ Medical illness } & No & 310 & 70 \\
\cline { 2 - 5 } & Yes & 341 & 78 \\
\hline \multirow{5}{*}{ physical exercise } & No & 96 & 22 \\
\cline { 2 - 5 } & Yes & 253 & 57.9 \\
\hline \multirow{5}{*}{ Exercises/mints } & Nothing & 184 & 42.1 \\
\cline { 2 - 5 } & Walking & 127 & 29.1 \\
\cline { 2 - 5 } & Running & 205 & 46.9 \\
\cline { 2 - 5 } & Lifting weight & 39 & 8.9 \\
\cline { 2 - 5 } & Playing sport games (Basketball, Football...) & 53 & 12.1 \\
\hline & $10-20$ mints & 108 & 3 \\
\cline { 2 - 5 } & $21-40$ mints & 114 & 34.8 \\
\cline { 2 - 5 } & $41-60$ mints & 54 & 17.4 \\
\cline { 2 - 5 } & More than one 60 mints & 34 & 11 \\
\hline
\end{tabular}

Table 3 Descriptive analysis of Physical exercise (PE)

\begin{tabular}{|c|c|c|c|c|c|c|}
\hline \multirow{2}{*}{ Item No. } & \multirow{2}{*}{ Level } & \multirow{2}{*}{$\mathrm{N} / \%$} & \multicolumn{3}{|c|}{ Frequencies } & \multirow{2}{*}{ Mean \pm SD } \\
\hline & & & Always & Sometimes & Never & \\
\hline \multirow{2}{*}{1} & Moderate & $\mathrm{N}$ & 105 & 182 & 23 & \multirow{2}{*}{$2.26 \pm 0.59$} \\
\hline & & $\%$ & $33.9 \%$ & $58.7 \%$ & $7.4 \%$ & \\
\hline \multirow{2}{*}{2} & Moderate & $\mathrm{N}$ & 23 & 192 & 95 & \multirow{2}{*}{$1.77 \pm 0.57$} \\
\hline & & $\%$ & $7.4 \%$ & $61.9 \%$ & $30.6 \%$ & \\
\hline \multirow{2}{*}{3} & Low & $\mathrm{N}$ & 16 & 54 & 240 & \multirow{2}{*}{$1.28 \pm 0.55$} \\
\hline & & $\%$ & $5.2 \%$ & $17.4 \%$ & $77.4 \%$ & \\
\hline \multirow{2}{*}{4} & High & $\mathrm{N}$ & 215 & 88 & 7 & \multirow{2}{*}{$2.67 \pm 0.52$} \\
\hline & & $\%$ & $69.4 \%$ & $28.4 \%$ & $2.3 \%$ & \\
\hline \multirow{2}{*}{5} & Moderate & $\mathrm{N}$ & 103 & 168 & 39 & \multirow{2}{*}{$2.21 \pm 0.65$} \\
\hline & & $\%$ & $33.2 \%$ & $54.2 \%$ & $12.6 \%$ & \\
\hline \multirow{2}{*}{6} & High & $\mathrm{N}$ & 147 & 145 & 18 & \multirow{2}{*}{$2.42 \pm 0.60$} \\
\hline & & $\%$ & $47.4 \%$ & $46.8 \%$ & $5.8 \%$ & \\
\hline 7 & High & $\mathrm{N}$ & 251 & 56 & 3 & $2.80 \pm 0.42$ \\
\hline
\end{tabular}




\begin{tabular}{|c|c|c|c|c|c|c|}
\hline & & $\%$ & $81 \%$ & $18.1 \%$ & $1 \%$ & \\
\hline \multirow{2}{*}{8} & High & $\mathrm{N}$ & 172 & 128 & 10 & \multirow{2}{*}{$2.52 \pm 0.56$} \\
\hline & & $\%$ & $55.5 \%$ & $41.3 \%$ & $3.2 \%$ & \\
\hline \multirow{2}{*}{9} & Moderate & $\mathrm{N}$ & 95 & 137 & 78 & \multirow{2}{*}{$2.05 \pm 0.75$} \\
\hline & & $\%$ & $30.6 \%$ & $44.2 \%$ & $25.2 \%$ & \\
\hline \multirow{2}{*}{10} & Low & $\mathrm{N}$ & 20 & 88 & 202 & \multirow{2}{*}{$1.41 \pm 0.61$} \\
\hline & & $\%$ & $6.5 \%$ & 28.45 & $65.2 \%$ & \\
\hline \multirow{2}{*}{11} & Low & $\mathrm{N}$ & 11 & 62 & 237 & \multirow{2}{*}{$1.27 \pm 0.52$} \\
\hline & & $\%$ & $3.5 \%$ & $20 \%$ & $76.5 \%$ & \\
\hline \multirow{2}{*}{12} & High & $\mathrm{N}$ & 241 & 61 & 8 & \multirow{2}{*}{$2.75 \pm 0.49$} \\
\hline & & $\%$ & $77.7 \%$ & $19.7 \%$ & $2.6 \%$ & \\
\hline \multirow{2}{*}{13} & High & $\mathrm{N}$ & 14 & 27 & 269 & \multirow{2}{*}{$2.82 \pm 0.49$} \\
\hline & & $\%$ & $4.5 \%$ & $8.7 \%$ & $86.8 \%$ & \\
\hline \multirow{2}{*}{14} & Moderate & $\mathrm{N}$ & 57 & 170 & 83 & \multirow{2}{*}{$1.92 \pm 0.67$} \\
\hline & & $\%$ & $18.4 \%$ & $54.8 \%$ & $26.8 \%$ & \\
\hline \multirow{2}{*}{15} & High & $\mathrm{N}$ & 3 & 38 & 269 & \multirow{2}{*}{$2.86 \pm 0.38$} \\
\hline & & $\%$ & $1 \%$ & $12.3 \%$ & $86.8 \%$ & \\
\hline \multirow{2}{*}{16} & Moderate & $\mathrm{N}$ & 117 & 161 & 32 & \multirow{2}{*}{$2.27 \pm 0.64$} \\
\hline & & $\%$ & $37.7 \%$ & $51.9 \%$ & $10.3 \%$ & \\
\hline
\end{tabular}

As demonstrated In Table (4) the Quality of Life scale had 4 domains and Overall Quality Life dimension. Transformed scale was measured using the following formula :

Transformed scale $=(\text { Actual raw score-Low possible score Possible raw score range })^{*} 100$

The Quality of Life and General Health was measured using two items ( 1 and 2$)$ the total mean score was $(6.63 \pm 1.78)$, range $=8$, with transformed scale $=57.88$. Physical Health was measured using seven items $(3,4,10,16,15,17$ and 18) the total mean score was $(20.73 \pm 4.32)$, range $=25$, with transformed scale $=50.94$. Psychological was measured using six items $(5,6,7,11,19$ and 26$)$ the total mean score was $(20.44 \pm 3.82)$, range $=19$, with transformed scale $=49.67$. Social Relationship was measured using three items $(20$, 21 and 22 ) the total mean score was $(9.85 \pm 2.72)$, range $=12$, with transformed scale $=57.12$. Environment was measured using eight items $(8,9,12,13,14,23,24$ and 25$)$ the total mean score was $(32.92 \pm 6.89)$, range $=32$, with transformed scale $=62.26$.

Table 4 Descriptive analysis of QOL domains and their transformed scale of WHO

\begin{tabular}{|c|c|c|c|c|c|c|}
\hline Domains and items & Range & Min & Max & Mean & SD & $\begin{array}{l}\text { Transformed } \\
\text { scale }\end{array}$ \\
\hline 1 & 4.00 & 1.00 & 5.00 & 3.43 & 0.91 & \multirow{3}{*}{57.88} \\
\hline 2 & 4.00 & 1.00 & 5.00 & 3.19 & 1.09 & \\
\hline $\begin{array}{l}\text { Overall Quality of Life and } \\
\text { General Health }\end{array}$ & 8.00 & 2.00 & 10.00 & 6.63 & 1.78 & \\
\hline 3 & 4.00 & 1.00 & 5.00 & 2.41 & 1.23 & \multirow{8}{*}{50.94} \\
\hline 4 & 4.00 & 1.00 & 5.00 & 1.92 & 1.19 & \\
\hline 10 & 4.00 & 1.00 & 5.00 & 3.12 & 1.06 & \\
\hline 15 & 4.00 & 1.00 & 5.00 & 3.57 & 1.02 & \\
\hline 16 & 4.00 & 1.00 & 5.00 & 3.17 & 1.19 & \\
\hline 17 & 4.00 & 1.00 & 5.00 & 3.35 & 1.13 & \\
\hline 18 & 4.00 & 1.00 & 5.00 & 3.21 & 1.12 & \\
\hline Physical Heath & 25.00 & 8.00 & 33.00 & 20.73 & 4.32 & \\
\hline 5 & 4.00 & 1.00 & 5.00 & 3.52 & 1.04 & \multirow{3}{*}{49.67} \\
\hline 6 & 4.00 & 1.00 & 5.00 & 3.65 & 1.08 & \\
\hline 7 & 4.00 & 1.00 & 5.00 & 3.27 & 0.96 & \\
\hline
\end{tabular}




\begin{tabular}{|c|c|c|c|c|c|c|}
\hline 11 & 4.00 & 1.00 & 5.00 & 3.17 & 1.20 & \\
\hline 19 & 4.00 & 1.00 & 5.00 & 3.34 & 1.13 & \\
\hline 26 & 4.00 & 1.00 & 5.00 & 3.49 & 1.06 & \\
\hline Psychological & 19.00 & 11.00 & 30.00 & 9.85 & 3.82 & \\
\hline 20 & 4.00 & 1.00 & 5.00 & 3.39 & 1.14 & \multirow{4}{*}{57.12} \\
\hline 21 & 4.00 & 1.00 & 5.00 & 2.91 & 1.29 & \\
\hline 22 & 4.00 & 1.00 & 5.00 & 3.57 & 1.19 & \\
\hline Social Relationship & 12.00 & 3.00 & 15.00 & 9.85 & 2.72 & \\
\hline 8 & 4.00 & 1.00 & 5.00 & 3.82 & 1.10 & \multirow{9}{*}{62.26} \\
\hline 9 & 4.00 & 1.00 & 5.00 & 3.24 & 1.10 & \\
\hline 12 & 4.00 & 1.00 & 5.00 & 3.75 & 1.13 & \\
\hline 13 & 4.00 & 1.00 & 5.00 & 3.88 & 0.91 & \\
\hline 14 & 4.00 & 1.00 & 5.00 & 3.16 & 0.97 & \\
\hline 23 & 4.00 & 1.00 & 5.00 & 3.80 & 1.21 & \\
\hline 24 & 4.00 & 1.00 & 5.00 & 3.73 & 1.14 & \\
\hline 25 & 4.00 & 1.00 & 5.00 & 3.77 & 1.25 & \\
\hline Environment & 32.00 & 13.00 & 45.00 & 32.92 & 6.89 & \\
\hline
\end{tabular}

One main purpose of the current study is to find out whether any differences of the quality of life based on the student exercise , the independent $t$ test was conducted, as shown in Table (5), exercised students were higher in the quality of the live for three domains than were non-exercised students $(\mathrm{p}<0.05)$, and indifferences for two domains ( $p>0.05)$. Overall Quality of Life and General Health was higher for exercised students for mean score $(6.93 \pm 1.71)(t=5.61, p<0.05)$ with mean differences $=1.02$. Physical Health was higher for exercised student for mean score $(21.21 \pm 4.29)(t=3.62, p<0.05)$ with mean differences $=1.62$. Psychological was higher for exercised student for mean score $(20.67 \pm 3.78)(\mathrm{t}=2.03, \mathrm{p}<0.05)$ with mean differences $=0.82$. The above results indicated that students who exercise had a better quality of life than who did not.

Table 5 difference between exercised students and non-exercised students according to their QOL

\begin{tabular}{|c|c|c|c|c|c|c|c|}
\hline \multicolumn{2}{|l|}{ Factor } & $\mathrm{N}$ & Mean & SD & $\mathrm{t}$ & $\mathrm{p}$ & Mean difference \\
\hline \multirow{2}{*}{$\begin{array}{l}\text { Overall Quality of Life } \\
\text { and General Health }\end{array}$} & Exercised & 310 & 6.93 & 1.71 & \multirow{2}{*}{$5.61^{* *}$} & \multirow{2}{*}{0.00} & \multirow{2}{*}{1.02} \\
\hline & Non-exercised & 127 & 5.91 & 1.77 & & & \\
\hline \multirow{2}{*}{ Physical Health } & Exercised & 310 & 21.21 & 4.29 & \multirow{2}{*}{$3.62^{* *}$} & \multirow{2}{*}{0.00} & \multirow{2}{*}{1.62} \\
\hline & Non-exercised & 127 & 19.58 & 4.19 & & & \\
\hline \multirow{2}{*}{ Psychological } & Exercised & 310 & 20.67 & 3.78 & \multirow{2}{*}{$2.03^{* *}$} & \multirow{2}{*}{0.04} & \multirow{2}{*}{0.82} \\
\hline & Non-exercised & 127 & 19.86 & 3.87 & & & \\
\hline \multirow{2}{*}{ Social Relationship } & Exercised & 310 & 9.91 & 2.71 & \multirow{2}{*}{0.60} & \multirow{2}{*}{0.55} & \multirow{2}{*}{0.19} \\
\hline & Non-exercised & 127 & 9.72 & 2.75 & & & \\
\hline \multirow{2}{*}{ Environment } & Exercised & 310 & 32.94 & 7.02 & \multirow{2}{*}{0.07} & \multirow{2}{*}{0.95} & \multirow{2}{*}{0.05} \\
\hline & Non-exercised & 127 & 32.89 & 6.61 & & & \\
\hline
\end{tabular}

\section{DISCUSSION}

The main destination of our study is to find out how is the QOL of female medical students affected by the physical exercise as the results have shown a statistical significance in between. A Portuguese systematic review showed that most cross-sectional studies reported a positive association between QOL and PE among various adult age groups (Ludendorff et al., 2016). The combined questionnaire had a variety of 44 different questions targeting detailed data about PE and QOL. For the PE, regular physical activities are protecting from getting depression, previous papers reported various benefits on general health, self esteem, and mood as it definitely decreases the chance of depression (Peluso \& Andrade, 2005; Mammen \& Faulkner, 2013; Jacka \& Berk , 2013). 
Fortunately $70 \%$ of the female medical students are regularly exercising moreover, $77.4 \%$ of them were not having fun while doing indicative of full awareness about the importance of exercises.

In contrast, a study was done in Brazil that had a $60 \%$ of exercised population resembling different papers in the USA and Canada 61\%, 64\% respectively (Peleias et al., 2017; Stanford et al., 2014; Ng \& Irwin, 2013). It seems as a constructive step on our part to be the first study to touch on different details including the type, timing of PE and the existence of medical illnesses. Walking gained the largest portion of our population interest 205 students with a percentage of (46.9\%), Running 39 students $(8.9 \%)$, Lifting weight 53 students (12.1\%), Playing sport games (Basketball, Football, etc.) 13 students (3\%). Based on scientific evidence, it's proven that at least 30 minutes of daily basis exercise can improve physical appearance, way of breathing and body functioning.

Most of our population prefers to exercise for 21 to 40 minutes (36\%) were $34.8 \%$ do PE from 10 to 20 minutes. On the other hand, physical inactivity is the primary reason for approximately $30 \%$ of ischemic heart diseases in general, $27 \%$ of diabetes and $21-$ $25 \%$ of colon and breast cancers (WHO, 2010; Lee et al., 2012). As demonstrated on our paper 22\% of the population are having medical issues that could be clarified by the young age group of our population they're having good health levels on average as well as low risk of developing diseases (Tol, 2013). A considerable attention is given to the extent of PE in medical students as it gives a forward-looking view of the future physicians there going to be. In fact, physically active physicians are considered having strong counseling skills regarding PE and healthy lifestyle. As previous papers discussed physicians who followed a routinely PE are up to 5.7 times more likely to counsel their patients about PE (Ng \& Irwin, 2013). Concerning QOL, it's challenging to deal with such a multidimensional definition as the QOL and the relations with PE, the domains including general health, social, physical, psychological and environmental. Since the QOL is subjective varying among different individuals and contexts and since the life of female medical students is loaded with various challenges our goal is to obtain the impact of PE on their QOL, whether all the domains are affected or not and which one is the most vulnerable.

In the KAUH female medical students community it's manifested that the environment, social relationships and general health what matters most of various QOL aspects (62.26\%, 57.12\%, 57.88\%) respectively. A recent paper, Gill et al., (2018) found out that university students of both genders valued more the physical health, social and emotional aspects of QOL. Additionally, Segar et al., (2011) on his paper confirmed that middle aged females are more focused on their psychological and social needs. Subsequently, we discovered a statistical significance between the PE with the general health, physical and psychological aspects of the QOL. According to our study, female medical students who are engaged in PE are more likely to be satisfied with their physical appearance and lifestyle as a consequence they own a high level of confidence and self esteem. In addition, steadily they're motivated and possess the capacity to work.

Taking into account, our focused group participants were all females with age limits and stationed in one medical campus. Those factors have implications for research and professional practice. Add to the fact that our study was a cross-sectional designed that does not allow definitive conclusions about causal relationships.

\section{CONCLUSION}

Eventually, after we discovered a strong association between PE and how is the QOL affected favorably it's recommended to upscale the awareness of PE in the entire Saudi community and for more comprehensive outcomes we advise the next researchers to use different study design.

\section{Ethical approval}

The study was approved by the biomedical ethics committee at King Abdul-aziz University hospital (KAUH), Jeddah, Saudi Arabia (ethical approval code: 21-22).

\section{Acknowledgement}

The authors gratefully thank the cooperation of the participants of this study.

\section{Author's contribution}

Dr. Ahmad Azhar: Shared in desiging the study and manuscript review.

Dr. Reem Ebraheem Aldaheri, Yara Faisal Alqurashi, Wafaa Mohammed Alalyani, and Albanderi Abdullah Albandar: designed the study, developed the questionnaire and the informed consent, wrote the protocol and planed the study, carried out data entry, statistical design and analysis. They carried out data collection, data entry and the statistical design. 


\section{Funding}

The study did not receive any external funding.

\section{Conflict of interests}

The authors declare that there are no conflicts of interests.

\section{Data and materials availability}

All data associated with this study are present in the paper.

\section{REFERENCES AND NOTES}

1. Alkhamis F, Almzraq LAA, Alshayeb ZK, AL-Jaziri ZY. Prevalence of premenstrual syndrome among medical students in King Faisal University in Alahssa-Saudi Arabia. Medical Science 2021;25(114):1971-1983

2. Alothman AM, Ahmed I, Alfadhel MA, Khalaf AM. The association between physical activity and burnout among medical students in Riyadh, Saudi Arabia. Medical Science 2021;25(115):2302-2310

3. Al-Zalabani AH, Al-Hamdan NA, Saeed AA. The prevalence of physical activity and its socioeconomic correlates in Kingdom of Saudi Arabia: A cross-sectional population-based national survey. J Taibah Univ Med Sci 2015;10(2):208-215. doi: 10.1016/j.jtumed.2014.11.001.

4. Cappelen AW, Charness G, Ekström M, Gneezy U, Tungodden B. Exercise improves academic performance. NHH Dept. of Economics Discussion Paper. 2017; 24(08), 148.

5. Ferguson B. ACSM's Guidelines for Exercise Testing and Prescription 9th Ed. 2014. J Can Chiropr Assoc 2014; 58:3, 328-329.

6. Gill DL, Hammond CC, Reifsteck EJ, Jehu CM, Williams RA, Adams MM, Lange EH, Becofsky K, Rodriguez E, Shang YT. Physical activity and quality of life. J Prev Med Public Health 2013; 46 Suppl 1(Suppl 1), S28-34. doi: 10.3961/jpmph.2013.46.S.S28.

7. Han GS. The relationship between physical fitness and academic achievement among adolescent in South Korea. J physic therap sci 2018; 30(4), 605-608. doi: 10.1589/jpts.30.605.

8. Jacka FN, Berk M. Depression, diet and exercise. Med J Aust 2013; 199(S6), S21-23. doi: 10.5694/mja12.10508.

9. Lee IM, Shiroma EJ, Lobelo F, Puska P, Blair SN, Katzmarzyk PT; Lancet Physical Activity Series Working Group. Effect of physical inactivity on major noncommunicable diseases worldwide: an analysis of burden of disease and life expectancy. Lancet 2012; 380(9838), 219-229. doi: 10.1016/S0140-6736(12)61031-9.

10. Ludendorff Queiroz L, Silveira de Brito C, Gomes de Almeida F, Martins Pereira N, de Almeida Silva H, Pena Porto J, Araújo Costa G, Gularte Agostini G, de Melo Costa Pinto R, Gontijo Filho PP, Marques Ribas R. Quality of life and impact of physical activity time in the health of elderly. Revista da Faculdade de Ciências Médicas de Sorocaba 2016;18(1),24-29. doi: 10.5327/Z1984-4840201623854.

11. Mammen G, Faulkner G. Physical activity and the prevention of depression: a systematic review of prospective studies. Am J Prev Med 2013; 45(5), 649-657. doi: 10.1016/j.amepre.2013.08.001.

12. Ng V, Irwin JD. Prescriptive medicine: the importance of preparing Canadian medical students to counsel patients toward physical activity. J Phys Act Health 2013; 10(6), 889899. doi: 10.1123/jpah.10.6.889.

13. Peleias M, Tempski P, Paro HB, Perotta B, Mayer FB, Enns SC, Gannam S, Pereira MA, Silveira PS, Santos IS, Carvalho CR. Leisure time physical activity and quality of life in medical students: results from a multicentre study. BMJ open sport exerc med 2017; 3(1):e000213. doi: 10.1136/bmjsem-2016-000213.

14. Peluso MA, Guerra de Andrade LH. Physical activity and mental health: the association between exercise and mood. Clinics (Sao Paulo) 2005; 60(1), 61-70. doi: 10.1590/s180759322005000100012

15. Rodríguez-Fernández A, Zuazagoitia-Rey-Baltar A, RamosDíaz E. Quality of life and physical activity: their relationship with physical and psychological well-being. Qual Life Qual Working Life 2017; 23:53-63. doi: 10.5772/intechopen.69151

16. Segar ML, Eccles JS, Richardson CR. Rebranding exercise: closing the gap between values and behavior. Int $\mathrm{j}$ behavior nutrit physic activity 2011; 8(1),94-108. doi: 10.1186/14795868-8-94.

17. Stanford FC, Durkin MW, Stallworth JR, Powell CK, Poston MB, Blair SN. Factors that influence physicians' and medical students' confidence in counseling patients about physical activity. J Prim Prev 2014; 35(3), 193-201. doi: 10.1007/s10935-014-0345-4.

18. Talebpour M, Aghaei M, Azimkhani A, Abbasian S, Ashkani A. A relationship between physical activity and healthy quality of life in students. Turkish J Sport Exercise 2014; 16(2):15-21. doi: 10.15314/TJSE.201428100.

19. Tol A, Tavassoli E, Shariferad GR, Shojaeezadeh D. Healthpromoting lifestyle and quality of life among undergraduate 
students at school of health, Isfahan University of medical sciences. J Educ Health Promot 2013; 28(2), 29-32. doi: 10.4103/2277-9531.108006.

20. World Health Organization (WHO). Global Recommendations on Physical Activity for Health. Geneva: World Health Organization; 2010. 2, Physical Activity for Health. Available from: https://www.ncbi.nlm.nih.gov/bo oks/NBK305049/

21. World Health Organization (WHO). Noncommunicable diseases: Risk factors, 2021. https://www.who.int/data/gho/ data/themes/topics/topic-details/GHO/ncd-risk-factors 